\title{
Psychological foundations of the concept of conflict behavior
}

\section{Gulmira BERDIEVA ${ }^{1}$}

Karshi state university

\begin{tabular}{l} 
ARTICLE INFO \\
\hline Article history: \\
Received December 2021 \\
Received in revised form \\
15 December 2022 \\
Accepted 20 January 2022 \\
Available online \\
15 Fabray 2022 \\
\hline Keywords: \\
cognitive, \\
dissonance, \\
conflict, \\
resolution, \\
approach-avoidance conflict, \\
avoidance-avoidance \\
conflict, \\
ambivalence.
\end{tabular}

\begin{abstract}
Conflicting behavior is more likely and often longer lasting than greater interdependence in a relationship. However, how the conflict will manifest itself will largely depend on the higher-quality characteristics of the relationship. The specific structure and theme of behavior used to manifest conflict is aggressiveness, intensity, persistence and other behavioral characteristics. This is manifested by possible formality or informality, stability or transience and orientation (a task against personal hostility), as well as aggravation of personal relationships.
\end{abstract}

2181-1415/@ 2022 in Science LLC.

DOI: https://doi.org/10.47689/2181-1415-vol3-iss1/S-pp26-31

This is an open access article under the Attribution 4.0 International (CC BY 4.0) license (https://creativecommons.org/licenses/by/4.0/deed.ru)

\section{Konfliktli xulq tushunchasining psixologik asoslari}

\begin{tabular}{l}
\hline Kalit so'zlar: \\
kognitiv, \\
dissonans, \\
konflikt, \\
hal qilish, \\
yondashuv-qochish \\
mojarosi, \\
qochish-qochish mojarosi, \\
ambivalentlik.
\end{tabular}

\begin{abstract}
ANNOTATSIYA
Konfliktli xatti-harakatlar ehtimoli ko'proq va, ko'pincha, bardoshli bo'lsa, munosabatlardagi o'zaro bog'liqlik shunchalik katta bo'ladi. Biroq ziddiyat qanday namoyon bo'lishi ko'p jihatdan munosabatlarning yuqori sifat xususiyatlariga bog'liq bo'ladi. Qarama-qarshilikni namoyon qilish uchun ishlatiladigan xatti-harakatlarning o'ziga xos repertuari - ularning tajovuzkorligi, intensivligi, qat'iyatliligi va boshqa xulq-atvor xususiyatlari - rasmiyatchilik yoki norasmiylik, barqarorlik yoki vaqtinchalik va munosabatlarning yo'nalishi (vazifaga nisbatan shaxsiy) bilan boshqariladi.
\end{abstract}

\footnotetext{
${ }^{1}$ Lecturer, Karshi state university. Karshi, Uzbekistan. E-mail: gulmira.juraeva@gmail.com.
} 


\section{Психологические основы концепции конфликтного поведения}

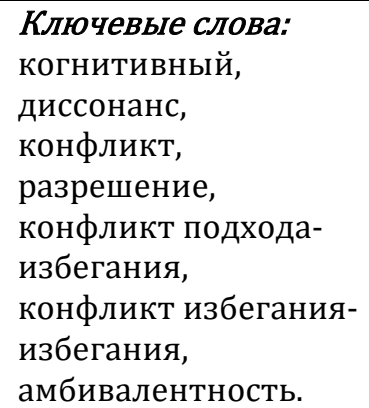

\begin{abstract}
АННОТАЦИЯ
Конфликтное поведение, более вероятно и часто более длительно, чем большая взаимозависимость в отношениях. Однако, то, как будет проявляться конфликт, будет во многом зависеть от более качественных характеристик отношений. Конкретная, структура и тема поведения, используемая для проявления конфликта - это агрессивность, интенсивность, настойчивость и другие поведенческие характеристики. Такое проявляется, возможной формальностью или неформальностью, стабильностью или быстротечностью и ориентацией (задача против личной неприязни), также обострения личных отношений.
\end{abstract}

Известно, что научное изучение явлений конфликта и внутреннего конфликта началось в конце 19 века и было связано с австрийским ученым, основателем психоанализа Зигмундом Фрейдом (1856-1939). Он определил биопсихологическую и биосоциальную природу внутреннего конфликта. Он показал, существование человека, находящегося в постоянном стрессе, биологическое состояние и социокультурные нормы человека, а также взаимосвязь между их желаниями (в основном сексуальными) между сознанием и бессознательным. Согласно Фрейду, эта конфронтация и постоянная борьба являются основой внутренних раздоров. В рамках психоанализа теорию внутреннего конфликта разработали Карл Юнг, Карен Хорн и другие. Немецкий психолог Курт Левин (1890-1947) внес значительный вклад в изучение проблемы внутреннего конфликта. Он определяет состояние как действие отдельной силы одинаковой величины и противоположного направления в одно и то же время. Вот почему существует три типа конфликтов. Человек находится между двумя равными положительными силами [1].

Дальнейшее развитие теории внутреннего конфликта, получила в творчестве многихпредставителей гуманистической психологии. Одной из ведущих фигур в этой области был американский психолог Карл Роджерс (19021987). По его словам, фундаментальной составляющей структуры человека является понятие «Я», которое представляет собой образ человека, образ «Я», который формируется в процессе взаимодействия человека с окружающей средой. На основе «Я-Концепции» человек контролирует свое поведение [2].

Однако «Я-концепция» часто несовместима с идеей «Я». Между ними может возникнуть протест. Этот диссонанс возникает как внутренний конфликт между «Я-концепцией» с одной стороны и «идеальным Я» с другой, и может привести к серьезным психическим заболеваниям. Известная на сегодняшний день, теория внутреннего конфликта была разработана австрийским ученым, психологом и психотерапевтом (1905) Виктором Франклом. Он создал новое направление в психотерапии - логотерапию. (Греч. Логос - мысль, созерцание и греч. Therapeia лечение). По его словам, логотерапия занимается смыслом человеческого существования и поиском этого содержания. Согласно концепции Фрэнка, главная 
движущая сила в жизни каждого человека - это находить ее содержание и бороться за это содержание жизни. Но не все люди, могут придавать смысл своей жизни. Недостаток ментального содержания создает в человеке экзистенциальное состояние, также, известное как чувство бесцельности и пустоты. Именно такой экзистенциальный вакуум порождает масштабные внутренние конфликты, которые с большой силой проявляются в «ноогенных неврозах» (греч. Noos содержание) [2].

По мнению автора теории, внутренние конфликты в виде ноогенного невроза вызываются психическими проблемами и связаны с нарушением «психического ядра личности». В этой форме ноогенный невроз - это нарушение внутренней структуры человека, которое вызвано отсутствием жизненного содержания человека, экзистенциальным вакуумом. Именно экзистенциальный вакуум, бесцельность и незначительность существования вызывают индивидуальное экзистенциальное разочарование на каждом этапе. Это часто проявляется в скуке и апатии. Следует отметить, что для психиатров скука - это скорее проблема, чем необходимость. Удовлетворить потребность легче, чем заскучать и апатично. Скука - это отсутствие смысла жизни, отсутствие значимых ценностей, что является серьезной проблемой, потому что найти смысл в жизни труднее, чем обрести богатство. Кроме того, потребность мотивирует человека двигаться, избавляться от невроза, а скука связана с экзистенциальным вакуумом, который усложняет человека и приводит к нарушению психологического развития.

Российские ученые А.Лурия, В. Мясищев, В. Мерлин и другие внесли значительный вклад в решение данных вопросов основываясь на результаты своих научных исследований. Во-первых, стоит отметить работы Леонтьева (19031979). Он интерпретирует концепцию проблемы внутреннего конфликта в теории, в роли активной деятельности в развитии личности. Согласно, его теории, наличие и состав внутреннего конфликта условно зависит от характера строения личности. Возможно, отметить, что, одна из важных характеристик внутренней структуры человека состоит в том, что никто не может жить одной целью и мотивом. Даже, если у него или нее есть ясный мотив и ведущий мотив в соответвующем поведении. А.Н. По словам Леонтьева, мотивационная сфера личности, никогда не напоминает застывшую пирамиду даже на высшей стадии развития личности. По мнению, Леонтьва, структура личности представляет собой устойчивую конфигурацию базовых вещей (внутренние иерархические, мотивационные линии). Дело в том, что возможно, неправильно описывается «направление человека», даже, в случае, если у человека есть четкий и ведущий образ жизни, предпологается, что он никогда не будет уникальным. В свою очередь, служение выбранной цели идеально подходит, для формирования мотивационных мотивов, которые не ограничивают и не охватывают другие аспекты жизни человека. Это, можно определить, как - мотивационное поле человека. Различные мотивы личности, на этих конфликтующих «пиках», являются мотивационной сферой, которая может породить внутренний конфликт [3].

Широко известна, концепция внутреннего конфликта американского психолога Абрахама Маслоу (1908-1968), одного из лидеров гуманистической психологии. По его словам, мотивационная структура личности состоит из ряда организованных иерархий потребностей: 
1. физические потребности;

2. потребность в безопасности;

3. потребность в любви;

4. потребность в уважении;

5. Необходимость использовать возможности

В.И. Курбатов «Конфликтология» Ростов-на-Дону «Феникс» 2007142 страница. В его интерпритации, человеческий потенциал, возможен на многое, а именно использование своих способностей и талантов. Такое проявляется в желании быть индивидуальностью, зная, кто, и что он может собой представлять. Такие представления не всегда возможны, чтобы такие представления не возникли, необходимо, внимание различных слоев общества. Это можно найти во многих людях, а также в умении привлекать их потенциал, но не у всех это реализуется. В основе этого внутреннего конфликта лежит пересечение между попыткой максимизировать свой потенциал и его реальным результатом [4].

Конфликт потребностей. Даный вывод, основан на том, что потребности, обычного человека, как правило, противоречат друг другу и могут побудить к неадекватным действиям. Да, отдельный субъект, может желать двух или более вещей, которые, могут, противоречать друг другу одновременно, их необходимо, рассматривать в разрезе. Например, ребенок требует сладкого. То есть, умоляет мать умоляет предоставить ему сладкое. Ребенок должен поесть и дать своей матери возможность, как минимум попробовать. В этой ситуации, ребенок чувствует конфликт потребностей и плачет.

Конфликт между потребностью и социальной нормой. Конфикт возможен, из-за разности во взлядах, в элементарных бытовых ситуациях. Следующий тип, внутреннего конфликта признал Зигмунд Фрейд на многих примерах. По его терминологии, противоречие, вызывающее этот тип конфликта, - это противоречие между «Ид» (U) и «Супер-эго» (Высшее Я). В то время как Ид фокусируется на агрессивных инстинктах, Супер - эго воплощает в себе ментальные нормы, запреты и стимулы, которые человек усваивает.

Конфликт социальных норм. Суть этого конфликта, в том, что чувствуется одинаковое давление двух противоречащих друг другу социальных норм. Стоит, обратить внимание, что различные конфликтные ситуации, представляет собой противоречие между классовым и религиозным долгом. Более четкую структуру классификации внутренних споров можно увидеть в работах А.Я. Ансупова, А.И. Шипилова. Данные авторы, изучают ценностно-мотивационную сферу индивида при помощи классификации. А именно, от того, какая сторона внутреннего мира человека приводит к конфликту, выделяют следующие основные типы:

Мотивационный конфликт. Это конфликт между бессознательными стремлениями, включающий две положительные тенденции: собственность и безопасность.

Моральный конфликт. Этот конфликт - конфликт между желанием и долгом. Другими словами, это конфликт между личным подчинением и духовными принципами.

Невыполненные пожелания или неполные споры. Такой конфликт, реализуется, между желаниями и действиями человека, который характеризуется своим собственным, отсутствием удовлетворения. Иногда, этот конфликт, 
трактуется как «Я хочу быть похожим на них», также анализируется, реальная невозможность этого желания. Этот конфликт, может возникнуть, когда человек физически не может выполнить свои духовные или физичекские желания. Например, человека не устраивает его внешний вид и физические возможности.

Вероятный конфликт. Этот конфликт, вызван невозможностью одновременно, выполнять несколько ролей (внутренний конфликт между ролями). К этому конфликту, возможно подойти следующим образом.

Например, когда, человеку поручают работать вне рабочего времени, в качестве сотрудника крупной организации. он намерен проводить свободное время со своими детьми. Хотя, такие ситуации требуют одного, жеременного присутствия человека между двумя ролями, которые могут привести, к конфликту внутренней неудовлетворенности.

Адаптивный конфликт. Этот спор имеет два значения. В самом широком смысле он основан на нарушении равенства между субъектом и окружающей средой, а в узком - на нарушении процесса социальной или профессиональной адаптации. Этот конфликт, возникает, между потребностями и способностями человека (профессиональными, физическими и умственными). Конфликты по поводу самооценки возникают между собственными возможностями человека и заявлением. Это может привести к сильному беспокойству и эмоциональному стрессу.

Невротический конфликт. Это результат, - последствие, простого внутреннего конфликта, который длится долгое время. Который, характеризуется высоким напряжением и борьбой с внутренними силами и мотивами человека. Перечисленные, выше виды споров, не имеют четкой классификации. История развития, концепции конфликтологии показывает, что существуют различные типы внутренних конфликтов. Такого рода, типы были разработаны разными учеными и исследователями в разное время, и интерпретировались с возможной, научной, точки зрения.

Фрустрация (лат. Frustratio - невыполнение планов, срыв) - психическое состояние человека, которое вызвано неясными объективными или субъективными трудностями в решении задачи или стремлении к цели.

Разочарование - всегда тяжелый опыт неудачи или конфликта для непосредственного лица. Это, можно рассматривать как форму психологического стресса. Разочарование - негативное следствие внутренних раздоров внутри личности, которые могут вызвать какие-либо психологические реакции. Что может вызвать, увеличивание напряжения терпимости к фрустрации, то есть формирование у человека устойчивости к фрустраторам. Такой подход, может сопровождаеться рядом отрицательных эмоций: гневом, нервозностью, чувством вины и так далее. Чем сильнее внутренний конфликт, тем глубже разочарование [5].

Различные личности могут относиться к данному вопросу по-разному. Каждый человек уникален в своей чувствительности, и у каждого есть свои собственные силы в преодолении фрустрирующих реакций на собственные внутренние конфликты.

Неврозы (греч. Нейрон-нерв). Это группа психогенных, более распространенных нервно-психических расстройств. Одна из важнейших причин неврозов - глубокие внутренние конфликты, которые нельзя разрешить позитивно и рационально. Возникновение невроза означает, что внутренний конфликт достиг уровня невротического конфликта. 
Короче говоря, преодоление и разрешение внутренних конфликтов посредством конфликта может, улучшить характер, волю и психологическую жизнь другого человека. Из этого абзаца можно сделать следующие выводы:

1. Конфликты мобилизуют ресурсы человека на развитие;

2. Конфликты способствуют самосознанию и самооценке человека;

3. Внутренний конфликт укрепляет волю и психику человека;

4. Это способ и средство саморазвития и самореализации;

5. Разрешение конфликтов позволяет человеку почувствовать себя полноценной и насыщенной жизнью. В этом случае внутренние конфликты позволяют нам подтолкнуть радость победы над собой, то есть человек приближает свое настоящее «Я»к идеальному «Я».

\section{БИБЛИОГРАФИЧЕСКИЕ ССЫЛКИ:}

1. Азимов Н.Ж. Динамика совместной учебной деятельности учителя со студентами. Автор дис. ... кандидат наук. Т., 1996.

2. Братченко С.Л. Межличностные конфликты - обычное дело. // Конфликт в конструктивной психологии. - Красноярск. 2008 г.

3. Гришина Н.В. Психология межличностного конфликта. Дис. на соискание степени доктора психологических наук. СПб., 1995.

4. Дейч М., Шикман С. Конфликт: социально-психологическая перспектива. М.: ИСАН, 1991. - С. 70-74.

5. Запрудский Ю.Г. Социальный конфликт. Ростов Н/Д, 2002.

6. Коряк Н.М. Влияние самооценки на поведение в условиях конфликта // Прикладные психолого-педагогические исследования в вузе. Новосибирск, 2002 г. 